\title{
X4 Tropic Virus Prediction Is Associated with a Nadir CD4 T-Cell Count below 100 Cells $/ \mathrm{mm}^{3}$
}

\author{
Matthieu Sechet ${ }^{a} \quad$ Catherine Roussel $^{\mathrm{a}}$ Jean-Luc Schmit ${ }^{\mathrm{a}}$ b Carlo Saroufim $^{c}$ \\ Kamel Ghomari ${ }^{d}$ Dominique Merrien ${ }^{e} \quad$ François Cordier ${ }^{f} \quad$ Jean-Jacques Pik $^{f}$ \\ Nathalie Landgraf ${ }^{f}$ Youcef Douadig Dominique Linéh Gilles Duverlie $^{a}$ \\ Sandrine Castelain ${ }^{a}$ \\ a'EA4294 Unité de Virologie Clinique et Fondamentale, UPJV et Centre Hospitalo-Universitaire, and \\ bMaladies infectieuses et tropicales, Centre Hospitalo-Universitaire, Amiens, 'Maladies infectieuses et tropicales, \\ Centre Hospitalier, and d Hémato-Oncologie, Centre Hospitalier, Beauvais, ${ }^{e}$ Médecine interne - Pathologies \\ Infectieuses, Centre Hospitalier, Compiègne, ${ }^{f}$ Médecine interne - Pathologies Infectieuses, Centre Hospitalier, \\ Creil, g Pneumologie et Maladies Infectieuses, Centre Hospitalier, Saint-Quentin, and ${ }^{\text {h}}$ Médecine interne - Maladies \\ Infectieuses, Centre Hospitalier, Soissons, France
}

\section{Key Words}

Tropism · Human immunodeficiency virus · Algorithm .

CD4 nadir · CCR5 - Maraviroc

\begin{abstract}
Objective: The aim of this study was to evaluate tropism prediction performances of three algorithms [geno2pheno false-positive rate $10 \%$ (G2P10), position-specific scoring matrix (PSSM) and a combination of the $11 / 25$ and net charge rules] and to investigate the viral and host factors potentially involved in the X4 or R5 prediction in human immunodeficiency virus-1 (HIV-1) patients. Methods: Viral tropism was determined in 179 HIV-1-infected patients eligible for CCR5 antagonist therapy. HIV-1 RNA or DNA was extracted and amplified for env gp120 sequencing. In parallel, demographic, viral, immunological and clinical determinants were analyzed. Results: According to the G2P10 algorithm, 48 patients harbored $X 4$ or X $4 R 5$ virus. The tropism prediction was concordant for 87.7 and $88.2 \%$ of samples when comparing G2P10 with PSSM or with a combination of the $11 / 25$ and net
\end{abstract}

(C) 2015 S. Karger AG, Basel

0300-5526/15/0583-0155\$39.50/0 charge rules, respectively. X4 prediction was significantly associated with more than 35 amino acids in the $\mathrm{V} 3$ domain $(\mathrm{p}<0.0001)$ and loss of an N-linked glycosylation site $(\mathrm{p}<$ $0.0001)$. Of the factors studied, only the nadir CD4 T-cell count was significantly associated with $X 4$ tropism $(p=0.01)$. Conclusion: We determined that the $\mathrm{X} 4$ virus detection is closely linked to the nadir CD4 T-cell count below 100 cells/ $\mathrm{mm}^{3}$ that must be taken into account when considering a CCR5 antagonist therapy switch.

(c) 2015 S. Karger AG, Basel

\section{Introduction}

Since the introduction of the specific CCR5 antagonist maraviroc into clinical practice, laboratory-based and clinical studies have focused on coreceptor usage by human immunodeficiency virus type 1 (HIV-1). Determining HIV coreceptor tropism is a prerequisite for the initiation of maraviroc treatment because HIV-1 can use the CCR5 and the CXCR4 membrane receptors (R5 and X4

\section{KARGER 125}

E-Mail karger@karger.com www.karger.com/int
Sandrine Castelain

Laboratoire de Virologie, Centre de Biologie Humaine CHU Hôpital Sud

FR-80054 Amiens Cedex (France)

E-Mail sandrine.castelain@u-picardie.fr 
viruses, respectively) or both (dual/mixed virus) to enter target cells. Although HIV-1 coreceptor tropism can be measured phenotypically with a few, highly complex, standardized assays, most patient screening for maraviroc treatment in Europe is based on genetic tropism testing (the amplification and sequencing of the V 3 domain of the viral envelope) [1]. Initially, the ' $11 / 25$ rule' and the 'net charge rule' were used to predict tropism from the V3 sequence but showed only a moderate correlation with the results of phenotypic assays $[2,3]$. Although the results of specific genotyping tools [such as geno2pheno and position-specific scoring matrix (PSSM)] are similar to those of the phenotypic assays, selection of a specific cutoff for the false-positive rate for geno2pheno is determinant in the chance of falsely predicting a virus as an $\mathrm{X} 4$ virus.

The selective pressure that leads to the emergence of either X4 or R5 virus is complex, and its relevance in the pathogenesis and natural history of HIV is still only partially understood [4-6]. Some studies suggest that the X4 virus is more pathogenic than the $\mathrm{R} 5$ virus because $\mathrm{X} 4$ is associated with faster decline in the CD4+ cell count, a high risk of clinical disease [7] and a lower baseline CD4+ cell count [8]. Recently, Soulié et al. [9] have shown that virus tropism has no impact on the change over time in CD4+ cell count in HIV-1 patients with $>350 \mathrm{CD} 4+$ cells $/ \mathrm{mm}^{3}$ at diagnosis. Taken as a whole, these findings suggest that other factors related to disease progression merit investigation.

Hence, we decided to analyze HIV-1 tropism in 179 HIV-1-infected patients eligible for anti-CCR 5 therapy by using 3 different algorithms [geno2pheno false-positive rate $10 \%$ (G2P10), PSSM and a combination of the 11/25 and net charge rules] and investigate the viral and host factors potentially implicated in the $\mathrm{X} 4$ or $\mathrm{R} 5$ prediction.

\section{Materials and Methods}

\section{Study Population}

Samples of plasma or peripheral blood mononuclear cells were obtained from $179 \mathrm{HIV}$-1-infected patients eligible for anti-CCR5 therapy. Following the provision of written, informed consent, patients were enrolled by 6 tertiary medical centers in the Picardy region of northern France from October 2010 to February 2013. Demographic and clinical data (age, gender, HIV risk factors, duration of HIV infection, antiretroviral exposure, CD4 nadir, current CD4 count, CD4/CD8 ratio and HIV RNA load) were collected and analyzed.

\section{Prediction of Viral Tropism}

HIV-1 RNA or DNA was extracted and amplified from plasma or peripheral blood mononuclear cells for env gp120 sequencing.

Briefly, V3 env was amplified and bulk sequenced. HIV-1 coreceptor usage was determined from the V3 env sequence using the G2P10 and PSSM bioinformatics tools with the syncytium-induc- ing/non-syncytium-inducing and X4/R5 matrices. Geno2pheno and PSSM are available at http://coreceptor.bioinf.mpi-inf.mpg. $\mathrm{de} /$ and http://indra.mullins.microbiol.washington.edu/webpssm/, respectively.

We also combined the genotypic rules based on the amino acid (aa) residues at $\mathrm{V} 3$ positions 11 and 25 (the 11/25 rule) and the overall net charge of the $\mathrm{V} 3$ sequence (the net charge rule) to predict HIV-1 tropism. One of the following criteria had to be met when predicting CXCR4 coreceptor usage: (i) $\mathrm{R}$ or $\mathrm{K}$ at position 11 of $\mathrm{V} 3$ and/or $\mathrm{K}$ at position 25, (ii) $\mathrm{R}$ at position 25 of $\mathrm{V} 3$ and a net charge of $\geq+5$, or (iii) a net charge of $\geq+6$. Viruses were classified as R5 (R5) or X4-tropic (X4/R5X4).

\section{Statistical Analysis}

The characteristics of patients classified as harboring an R5 or non-R5 virus were compared and tested for statistical significance using the nonparametric Mann-Whitney test for continuous variables and $\chi^{2}$ or Fisher's exact test for categorical variables. A 2-sided $p$ value of $\leq 0.05$ was considered statistically significant.

\section{Results}

A total of 179 samples (subtype B: $114 ; 63.7 \%$ ) from HIV-1-infected patients (110 men and 69 women; mean age \pm standard deviation: $43.6 \pm 10.3$ years) were analyzed. The mean CD4 T-cell count was $448 \pm 298$ cells/ $\mathrm{mm}^{3}$, and $17.8 \%$ of the patients had a count below 200 cells $/ \mathrm{mm}^{3}$. The mean plasma HIV-1 RNA was $3.17 \pm 1.67$ $\log 10 \mathrm{HIV}-1$ RNA copies/ml. $17.8 \%$ of the individuals were antiretroviral treatment naïve.

The 179 V3 loop sequences were analyzed for tropism using the G2P10, PSSM and a combination of the 11/25 and net charge rules. All 179 sequences were recognized by the three algorithms. Of these, 131 (73\%) and 48 (27\%) were classified as $\mathrm{R} 5$ and $\mathrm{X} 4$ viruses, respectively, using G2P10 (table 1). The tropism predictions were concordant for 157 (87.7\%) samples when comparing G2P10 with PSSM and 158 (88.2\%) when comparing G2P10 with a combination of the $11 / 25$ and net charge rules.

The aa positions of the V3 loop sequences were also analyzed as a function of G2P10 tropism. X4 viruses were significantly associated with a V3 length $>35$ aa, a net charge $>+5$ and loss of V3's N-linked glycosylation site $(\mathrm{p}<0.0001$; table 1$)$.

The baseline clinical, immunological and virological characteristics of the 179 patients are shown in table 2. Of the various factors studied (time since diagnosis of HIV infection, age, gender, viral load, risk factors, CDC stage, $\mathrm{CD} 4 / \mathrm{CD} 8$ ratio, and nadir and current CD4 cell counts), only the nadir CD4 T-cell count was significantly associated with virus tropism $(\mathrm{p}=0.028)$. The mean nadir CD4 cell count was $151 \pm 125.7$ cells $/ \mathrm{mm}^{3}$ in patients with X4/ 
Table 1. Tropism prediction performances of the three algorithms and specific characteristics of V3 loop sequences as a function of the viral tropism
Table 2. Baseline characteristics of the R5 and X4/R5X4 subgroups as a function of the G2P10 viral tropism

\begin{tabular}{llll}
\hline & G2P10 & & \\
\cline { 2 - 4 } & $\mathrm{R} 5(\mathrm{n}=131)$ & $\mathrm{X} 4 / \mathrm{R} 5 \mathrm{X} 4(\mathrm{n}=48)$ & p value \\
\hline PSSM & 145 & 34 & \\
Combination of the 11/25 and net charge & 154 & 25 & $<0.0001$ \\
$\quad$ rules & 0 & $6(13)$ & 0.238 \\
N-linked glycosylation site mutation & $17(13)$ & $10(21)$ & $<0.0001$ \\
GAG motif mutation & $2(1.5)$ & $15(31)$ & $<0.0001$ \\
Net charge $>+5$ & 0 & $6(13)$ & \\
Length of $\mathrm{V} 3>35$ aa & & & \\
\hline
\end{tabular}

Figures in parentheses indicate percentages.

\begin{tabular}{|c|c|c|c|}
\hline Characteristic & $\begin{array}{l}\mathrm{R} 5 \\
(\mathrm{n}=131)\end{array}$ & $\begin{array}{l}\mathrm{X} 4 / \mathrm{R} 5 \mathrm{X} 4 \\
(\mathrm{n}=48)\end{array}$ & $\mathrm{p}$ value \\
\hline Mean age \pm SD at sample collection, years & $43 \pm 11$ & $44.2 \pm 8.8$ & 0.47 \\
\hline \multicolumn{4}{|l|}{ Gender, $\mathrm{n}$} \\
\hline Female & $53(40.4)$ & $16(33.3)$ & \multirow[t]{2}{*}{0.49} \\
\hline Male & $78(59.5)$ & $32(66.7)$ & \\
\hline Mean HIV RNA, log10 copies/ml & $2.91 \pm 2.15$ & $2.78 \pm 1.91$ & 0.50 \\
\hline Median current CD4 cell count, $\mathrm{n} / \mathrm{mm}^{3}$ & $454 \pm 297$ & $447.3 \pm 306.7$ & 0.93 \\
\hline Median current CD4/CD8 ratio & $0.65 \pm 0.56$ & $0.51 \pm 0.40$ & 0.28 \\
\hline \multicolumn{4}{|l|}{ Time since diagnosis of HIV infection, $\mathrm{n}$} \\
\hline$<10$ years & $61(46.5)$ & $21(43.7)$ & \multirow[t]{3}{*}{0.29} \\
\hline$>10$ years & $49(37.5)$ & $25(52.1)$ & \\
\hline n.d. & $21(16.0)$ & $2(4.2)$ & \\
\hline Median nadir CD4 cell count, $\mathrm{n} / \mathrm{mm}^{3}$ & $235 \pm 215.2$ & $151 \pm 125.7$ & 0.02 \\
\hline \multicolumn{4}{|l|}{ Nadir CD4 cell count, $\mathrm{n}$} \\
\hline$<100 / \mathrm{mm}^{3}$ & $30(22.9)$ & $21(43.8)$ & \multirow[t]{3}{*}{0.01} \\
\hline$>100 / \mathrm{mm}^{3}$ & $83(63.4)$ & $21(43.8)$ & \\
\hline n.d. & $18(13.7)$ & $6(12.4)$ & \\
\hline \multicolumn{4}{|c|}{ Time between nadir CD4 and the determination of HIV tropism, $\mathrm{n}$} \\
\hline$<5$ years & $61(46.5)$ & $21(43.7)$ & \multirow[t]{3}{*}{0.35} \\
\hline$>5$ years & $39(29.8)$ & $20(41.7)$ & \\
\hline n.d. & $31(23.7)$ & $7(14.6)$ & \\
\hline \multicolumn{4}{|l|}{ CDC stage, $\mathrm{n}$} \\
\hline A & $83(63.3)$ & $27(56.2)$ & \multirow[t]{4}{*}{0.36} \\
\hline $\mathrm{B}$ & $12(9.2)$ & $8(16.7)$ & \\
\hline $\mathrm{C}$ & $27(20.6)$ & $11(22.9)$ & \\
\hline n.d. & $9(6.9)$ & $2(4.2)$ & \\
\hline \multicolumn{4}{|l|}{ Risk factor, n } \\
\hline Sexual factors & $102(77.8)$ & $38(79)$ & \multirow[t]{3}{*}{0.73} \\
\hline Parenteral factors & $9(6.9)$ & $2(4.2)$ & \\
\hline n.d. & $20(15.3)$ & $8(16.8)$ & \\
\hline ARV exposure (naïve), n & $25(19.1)$ & $7(14.6)$ & 0.65 \\
\hline
\end{tabular}

Figures in parentheses indicate percentages. n.d. = Not determined; ARV $=$ antiretroviral. 
$\mathrm{R} 5 \mathrm{X} 4$ viruses and $235 \pm 215.2$ cells $/ \mathrm{mm}^{3}$ in patients with $\mathrm{R} 5$ viruses. In contrast, there was no significant intergroup difference in the mean current CD4 cell count (454 \pm 297 cells $/ \mathrm{mm}^{3}$ for R5 and $447.3 \pm 306.7$ cells $/ \mathrm{mm}^{3}$ for $\mathrm{X} 4 / \mathrm{R} 5 \mathrm{X} 4$ viruses; $\mathrm{p}=0.93$ ). Interestingly, a nadir CD4 cell count below 100 cells $/ \mathrm{mm}^{3}$ was strongly associated with the results of tropism prediction ( $\mathrm{p}=0.012$; table 2$)$.

\section{Discussion}

Given that the prediction of HIV coreceptor tropism in general and R5 status in particular is a prerequisite for maraviroc treatment, we compared the predictive ability of three genotype-based algorithms that analyze the V3 loop gp120 sequence.

The overall degrees of concordance between pairs of algorithms (87.7\% for G2P10 vs. PSSM and $88.2 \%$ for G2P10 vs. a combination of the $11 / 25$ and net charge rules) were similar to previously published values [10]. However, we observed that PSSM and the combination of the $11 / 25$ and net charge rules detected $\mathrm{X} 4$ viruses less frequently than G2P10 did.

We also performed a detailed analysis of each aa position in the 179 sequences as a function of the G2P10 tropism prediction. Specific V3 loop motifs (such as asparagine mutations leading to the loss of the $\mathrm{N}$-linked glycosylation site, and a length $>35$ aa) are significantly associated with $\mathrm{X} 4$ prediction. A previous study has emphasized that a change in the number of aa may complicate sequence alignment and genotropism prediction with the PSSM algorithm [10]. In the present study, all sequences were correctly processed by all three algorithms. However, the association between the V3 sequence comparison and differences in tropism prediction highlighted the importance of a length $>35$ aa.

The presence or absence of an N-linked glycosylation site within the V3 loop reportedly influences coreceptor tropism $[11,12]$. It has been demonstrated that glycans are covalently linked to specific asparagine residues within the envelope precursor protein gp160 by the host cell machinery and are important for the correct, stable folding of gp120. The results of a recent study suggested that the presence of $\mathrm{N}$-linked glycans has a significant impact on the dynamics of the gp 120 protein (particularly the movement and preferred conformation of the V3 loop) and that N-linked glycosylation has a role in determining HIV-1 coreceptor tropism [13]. In the present study, mutations of the asparagine residues in the V3 loop were significantly correlated with $\mathrm{X} 4$ prediction $(\mathrm{p}<0.0001)$.

Lastly, we analyzed demographic, virological, immunological and clinical determinants. Of the various factors studied, only the nadir CD4 T-cell count alone was significantly associated with $\mathrm{X} 4$ tropism $(\mathrm{p}=0.01)$. The association was especially strong for a nadir count below 100 cells $/ \mathrm{mm}^{3}$ ( $\mathrm{p}=0.02$ ). In contrast, current CD4 cell counts were not significantly associated with $\mathrm{X} 4$ tropism. A longitudinal study of the emergence of X4 virus in seroconverters for more than 10 years has shown that there is a relationship between the emergence of X4 or X4/R5 virus and disease progression (as evidenced by a decrease in CD4 T-cell count) [14]. However, it has also been reported that the presence of X4 virus in HIV-1-infected patients with $>350 \mathrm{CD} 4+$ cells $/ \mathrm{mm}^{3}$ at diagnosis has no impact on the change over time in the CD4+ cell count [9]. Although the mean CD4 T-cell count was $448 \pm 298$ cells $/ \mathrm{mm}^{3}$ in our study population, the presence of X4 virus was closely associated with the nadir $\mathrm{CD} 4 \mathrm{~T}$-cell count value. The latter might be of value as an additional marker in patient care.

In conclusion, it has not yet been definitively established whether $\mathrm{X} 4$ viruses have a role in the pathogenesis of HIV but the nadir CD 4 cell count appears to be a key marker and must be taken into account when considering the initiation of CCR5 antagonist therapy.

\section{References}

1 Poveda E, Seclén E, González M del M, García F, Chueca N, Aguilera A, Rodríguez JJ, González-Lahoz J, Soriano V: Design and validation of new genotypic tools for easy and reliable estimation of HIV tropism before using CCR5 antagonists. J Antimicrob Chemother 2009;63:1006-1010.

2 Poveda E, Alcamí J, Paredes R, Córdoba J, Gutiérrez F, Llibre JM, Delgado R, Pulido F, Iribarren JA, García Deltoro M, Hernández Quero J, Moreno S, García F: Genotypic determination of HIV tropism - clinical and methodological recommendations to guide the therapeutic use of CCR5 antagonists. AIDS Rev 2010;12:135-148.

-3 Vandekerckhove L, Verhofstede C, Demecheleer E, De Wit S, Florence E, Fransen K, Moutschen M, Mostmans W, Kabeya K, Mackie N, Plum J, Vaira D, Van Baelen K, Vandenbroucke I, Van Eygen V, Van Marck H, Vogelaers D, Geretti AM, Stuyver LJ: Comparison of phenotypic and genotypic tropism determination in triple-class-experienced HIV patients eligible for maraviroc treatment. J Antimicrob Chemother 2011;66: 265-272. 
4 Saracino A, Monno L, Scudeller L, Bruno G, Ladisa N, Punzi G, Volpe A, Lagioia A, Angarano G: $\mathrm{X} 4$ viruses are frequently archived in patients with long-term HIV infection but do not seem to influence the 'inflamm-aging' process. BMC Infect Dis 2013;13:220.

5 Moore JP, Kitchen SG, Pugach P, Zack JA: The CCR5 and CXCR4 coreceptors - central to understanding the transmission and pathogenesis of human immunodeficiency virus type 1 infection. AIDS Res Hum Retroviruses 2004;20:111-126.

-6 Zaitseva M, Peden K, Golding H: HIV coreceptors: role of structure, posttranslational modifications, and internalization in viralcell fusion and as targets for entry inhibitors. Biochim Biophys Acta 2003;1614:51-61.

7 De Mendoza C, Rodriguez C, García F, Eiros JM, Ruíz L, Caballero E, Aguilera A, Leiva P, Colomina J, Gutierrez F, del Romero J, Aguero J, Soriano V; Spanish HIV Seroconverter Study Group: Prevalence of X4 tropic viruses in patients recently infected with HIV-1 and lack of association with transmission of drug resistance. J Antimicrob Chemother 2007;59: 698-704.
\$8 Goetz MB, Leduc R, Kostman JR, Labriola AM, Lie Y, Weidler J, Coakley E, Bates M, Luskin-Hawk R; Long-Term Monitoring Study (CPCRA 060) and Terry Beirn Community Programs for Clinical Research on AIDS (CPCRA): Relationship between HIV coreceptor tropism and disease progression in persons with untreated chronic HIV infection. J Acquir Immune Defic Syndr 2009;50: 259-266.

-9 Soulié C, Charpentier C, Flandre P, Nino C, Carcelain G, Simon A, Katlama C, Landman R, Brun-Vézinet F, Descamps D, Calvez V, Marcelin AG: Natural evolution of CD4+ cell count in patients with CD4 $>350$ or $>500$ cells $/ \mathrm{mm}^{3}$ at the time of diagnosis according to HIV-1 coreceptor tropism. J Med Virol 2012;84:1853-1856.

10 Soulié C, Derache A, Aimé C, Marcelin AG, Carcelain G, Simon A, Katlama C, Calvez V: Comparison of two genotypic algorithms to determine HIV-1 tropism. HIV Med 2008;9: $1-5$.
1 Pollakis G, Kang S, Kliphuis A, Chalaby MI, Goudsmit J, Paxton WA: N-linked glycosylation of the HIV type-1 gp120 envelope glycoprotein as a major determinant of CCR5 and CXCR4 coreceptor utilization. J Biol Chem 2001;276:13433-13441.

12 Polzer S, Dittmar MT, Schmitz H, Schreiber M: The N-linked glycan g15 within the V3 loop of the HIV-1 external glycoprotein gp120 affects coreceptor usage, cellular tropism, and neutralization. Virology 2002;304: 70-80.

13 Wood NT, Fadda E, Davis R, Grant OC, Martin JC, Woods RJ, Travers SA: The influence of N-linked glycans on the molecular dynamics of the HIV-1 gp120 V3 loop. PLoS One 2013;8:e80301.

14 Shepherd JC, Jacobson LP, Qiao W, Jamieson BD, Phair JP, Piazza P, Quinn TC, Margolick JB: Emergence and persistence of CXCR4tropic HIV-1 in a population of men from the multicenter AIDS cohort study. J Infect Dis 2008;198:1104-1112. 